\title{
Examining Cyber Bullying and Cyber Victimization in High School Students
}

Demet Pekşen Süslü

Maltepe University, Child Development

\begin{abstract}
The aim of this research is to examine some variables related to cyber bullying and cyber victimization in high school students. It was investigated whether there is a difference for cyber bullying and cyber victimization behaviours, in terms of gender, age, type of school, parents' education, having of computer/mobile phone/tablet, the frequency of using the internet and place where they are connecting to the internet. The study is conducted using a correlational method. Research group consisted of 1085 students. The age of the students in this study is between 14-17. For the analysis of research data, Mann-Whitney $U$ test, KruskalWallis test and Post-Hoc Mann-Whitney $U$ test were applied. According to the findings of study, there is no significant difference for the cyber bullying grades in terms of parents' education, the types of school and place where students are connecting to the internet. There is no significant difference for the cyber victimization grades in terms of gender, age and mothers' education. Cyber bullying grades of 16 years old students are higher than the other age groups. State school students' cyber victimization grades are higher than private school students'. Additionally, for the period they use the internet, it was seen that cyber bullying and cyber victimization grades are higher for the students using the internet more than 3 hours. In terms of cyber victimization grades it was obtained that the grades of students connecting to the internet from a mobile phone are higher than the students connecting to the internet at home.
\end{abstract}

Keywords: cyber bullying, cyber victimization, adolescents 